\title{
O trabalho cooperativo entre bibliotecários e professores para o desenvolvimento da competência em informação: criação de um programa voltado para alunos do ensino médio ${ }^{1}$
}

\author{
Cooperative work between librarians and teachers for the development of information \\ literacy: the creation of a program for high school students
}

\begin{abstract}
Ane Fonseca
Graduada em Biblioteconomia pela Universidade Federal do Estado do Rio de Janeiro - UNIRIO.

E-mail: hannefonseca@ hotmail.com

Daniela Spudeit

Mestre em Ciência da Informação pela Universidade Federal de Santa Catarina - UFSC. Professora no curso de Biblioteconomia da Universidade do Estado de Santa Catarina - UDESC.

E-mail: danielaspudeit@gmail.com
\end{abstract}

\begin{abstract}
Resumo
O presente trabalho procura investigar como a competência em informação é desenvolvida pelos professores e bibliotecários focando nos serviços realizados em um dos campi do Colégio Pedro II localizado no estado do Rio de Janeiro. Dessa forma, foi realizada uma pesquisa bibliográfica, exploratória e descritiva para verificar por meio de entrevistas as atividades conjuntas realizadas pelos professores e bibliotecários na instituição. A partir disso, foi elaborado um programa sistematizado para o desenvolvimento de competências em informação para os alunos do ensino médio com ações e indicadores de avaliação. Dessa forma, acredita-se que seja possível contribuir para a formação integral do aluno por meio de ações que permitam uma reflexão ativa e crítica de sua aprendizagem.
\end{abstract}

Palavras-chave: Competência em Informação. Biblioteca escolar. Ensino Médio. Colégio Pedro II.

\begin{abstract}
This paper aims to investigate the information competence is developed by teachers and librarians focusing on services performed in one how of the Colégio Pedro II campuses located in the state of Rio de Janeiro. Thus, a literature, exploratory and descriptive study was performed to verify through interviews joint activities undertaken by teachers and librarians in the institution. From this, a systematic program for the development of skills in information for high school students with actions and evaluation indicators was prepared. Thus, it is believed that it is possible to contribute to the integral formation of the student through actions that allow an active and critical reflection of their learning.
\end{abstract}

Keywords: Information Literacy. School library. High school. Colégio Pedro II.

\footnotetext{
${ }^{1}$ Resultado do Trabalho de Conclusão de Curso em Biblioteconomia pela Universidade Federal do Estado do Rio de Janeiro (UNIRIO) defendido em junho de 2015 aprovado com nota máxima.
}

Bibl. Esc. em R., Ribeirão Preto, v. 5, n. 1, p. 36-63, 2016. 
Ane Fonseca e Daniela Spudeit

\section{Introdução}

A escola é, durante muito tempo, o ambiente onde um indivíduo adquire grande parte de sua experiência cultural e que possui um papel fundamental para sua formação. Dentro da escola que o aluno desenvolve sua relação com a sociedade e o modo como ele virá a contemplar o mundo. O papel do professor durante toda essa jornada é de extrema importância, pois ele agirá como um mediador que expõe a seus alunos os conceitos e informações existentes no mundo mostrando os diferentes caminhos.

Além do professor, existem outros profissionais que auxiliam o aluno durante o processo da formação de sua identidade e na construção do conhecimento. Um destes profissionais é o bibliotecário que também tem a tarefa de mediar a aprendizagem dos alunos e apresentar diferentes fontes e recursos de informação.

A parceria entre professores e bibliotecários nas escolas deve ser vista como algo de fundamental importância, pois, a partir do trabalho em conjunto, será possível criar uma influência positiva para o estudante e sua formação plena. Ao complementar o trabalho um do outro, é possível ir além dos conteúdos dos livros didáticos, permitindo o acesso às informações relevantes e pertinentes, conhecimentos sobre o mundo e a sociedade, vistos através de olhares críticos.

Ao trabalharem unidos subsidiados pelas tecnologias e recursos atuais, bibliotecários e professores devem ser capazes de propiciar um ambiente em que os alunos possam desenvolver competências para uma formação crítica e reflexiva capazes de analisar prós e contras de qualquer situação do cotidiano, num constante aprender a aprender.

Dentro deste contexto, torna-se importante que esses educadores desenvolvam atividades juntos para tornar os alunos cada vez mais aptos na busca, na organização, na recuperação, na análise e no uso da informação disponível em todos os suportes para formar cidadãos competentes em informação na atual sociedade que exige uma aprendizagem mais significativa. 
O trabalho cooperativo entre bibliotecários e professores para o desenvolvimento da competência em informação: criação de um programa voltado para alunos do ensino médio

\section{O papel da biblioteca escolar por uma aprendizagem significativa}

A busca pela aprendizagem significativa e a produção de um conhecimento construído com base em suas próprias experiências caracteriza a Sociedade da Aprendizagem, algo que se almeja chegar. Essa sociedade é caracterizada pela tentativa de se transformar a informação em conhecimento, sendo composta por indivíduos que buscam ir além da informação superficial, procurando formar um conhecimento baseado na analise e reflexão dos dados obtidos. Sua principal atividade é o processo de aprendizagem, que por sua vez "depende de um pensamento reflexivo e ético, resultado da mudança na consciência humana que o conhecimento gerado pela informação é capaz de promover” (GASQUE, TESCAROLO, 2004, p. 36).

A respeito da aprendizagem significativa, Belluzzo e Feres (2013, p.71) explica que ela ocorre "a partir de uma nova informação ancorada (assimilada) em conhecimentos preexistentes na estrutura cognitiva de quem aprende (que são significativos para ele) ". Portanto, a aprendizagem é o principal caminho para a construção de uma sociedade que faça mais do que simplesmente consumir a informação, mas que seja uma sociedade constituída por cidadãos competentes e criteriosos no trato da informação.

Em uma sociedade da aprendizagem deve-se aprender a utilizar as ferramentas necessárias para se transformar a informação em conhecimento. Nesse sentido, para Gasque e Tescarolo (2004) a informação seria a "coisa" a ser compreendida; esse processo de compreensão, porém, depende do desenvolvimento do pensamento reflexivo, que permitirá a construção do sentido.

A educação no século XXI deve ser vista como uma nova forma de reger a sociedade, pois ela oferece ao ser humano os meios necessários para desenvolver as suas potencialidades e permite que todos, sem exceção, sejam capazes de frutificar seus talentos, ou seja, a parte intrínseca do desenvolvimento de uma pessoa.

Para Delors (2010) é imperativo impor o conceito de educação ao longo da vida, com suas vantagens de flexibilidade, diversidade e acessibilidade. Ela deve ser uma construção contínua da pessoa, que precisa entender as mudanças da vida, seu saber e aptidões. Contudo, para estarem em condições de usar corretamente todas as suas potencialidades, os indivíduos devem dispor de todos os elementos de uma educação básica de qualidade. 
Ane Fonseca e Daniela Spudeit

Aprender no século XXI não é somente entender e compreender o que os professores dizem em sala de aula, mas também utilizar suas próprias experiências e ensinamentos obtidos ao longo da vida, para que dessa forma seja possível gerar um novo conhecimento.

A sociedade contemporânea vive uma gigante rotina de transformações e inovações, logo a educação parece ser a chave para preencher as lacunas criadas pelos constantes avanços tecnológicos, daí o desafio de aprender a aprender.

Aquino (2012) afirma que a compreensão de ensino e aprendizagem foi alterada pelo advento das novas tecnologias que nos fizeram reconhecer que grande parte do conhecimento adquirido ao longo da vida está desatualizado diante dos paradigmas emergentes da cultura.

A partir desse ponto deve ser pensado o tema da educação continuada, que permitirá que as pessoas sejam capazes de transformar informação em conhecimento. Para todo esse processo (de educação continuada) aconteça, Delors (2010) apresenta o que seriam os quatro pilares da educação- Aprender a conviver, aprender a conhecer, aprender a fazer e aprender a ser - que devem nortear a formação de um cidadão no século XXI.

Esses quatro pilares devem ser trabalhados em ambiente escolar, a fim de possibilitarem a formação de adultos capazes de produzirem conhecimento a partir das informações que recebem e essa produção somente é possível por meio do processo de aprendência que Aquino (2012, p. 45) explica como sendo "o processo e a experiência de aprendizagem, tendo explicita a ideia de vivência e experiência".

Consequentemente, a escola, por meio de uma educação de qualidade, acaba sendo o espaço propício para a formação de um adulto capaz de interagir de maneira eficaz na sociedade, são os ensinamentos aprendidos com os professores que ajudam no crescimento de jovens com pensamentos críticos e relevantes e que serão capacitados para alcançarem seus objetivos.

A educação é uma chave para ajudar indivíduos a sair da pobreza e evitar que essa seja passada de geração em geração. Ela possibilita melhores salários aqueles que têm empregos formais pagos e oferece melhor qualidade de vida aos que trabalham na agricultura e nos setores informais (UNESCO, 2014, p. 22).

Entretanto, é necessário que o aprendizado em sala de aula possua significado para o aluno, ou seja, é preciso que os alunos realizem links entre o que é ensinado e os conhecimentos que eles que eles já trazem dentro de si. Esse processo recebe o nome de aprendizagem significativa, o que nada mais é do que o processo de relacionamento da nova informação com 
O trabalho cooperativo entre bibliotecários e professores para o desenvolvimento da competência em informação: criação de um programa voltado para alunos do ensino médio

um conhecimento relevante já existente no indivíduo. De acordo com Moreira e Masini (1982, p. 7) "a aprendizagem significativa ocorre quando a nossa informação se ancora em conceitos relevantes preexistentes na estrutura cognitiva de quem aprende”.

Portanto, a aprendizagem significativa somente é possível quando a informação recebida cria laços e pontos em comum com a estrutura cognitiva do individuo, ou seja, quando passa a existir uma interação entre o que se aprendeu e os conceitos, abstrações e experiências do indivíduo.

Ontoria Peña (2005, p. 18) afirma que a estrutura cognitiva do indivíduo é "o fator que decide a respeito da significação do novo material e de sua aquisição e sua retenção". A aprendizagem significativa, portanto, permite a construção do conhecimento, possibilitando que o indivíduo crie, por meio da assimilação, novas informações que incluíram os conhecimentos que já possuía e os adquiridos, permitindo assim, um processo de aprendizagem continua.

Todavia, para que a construção do conhecimento seja uma realidade em sala de aula, é necessário que o professor respeite as experiências de seus alunos, permitindo que eles sejam participantes do processo de ensino, usando a sua curiosidade como aliada para a educação e não minando ou ironizando as tentativas de construção do conhecimento. Freire (2013, p. 58) afirma que:

O professor que desrespeita a curiosidade do educando, o seu gosto estético, a sua inquietude, a sua linguagem, mais precisamente a sua sintaxe e a sua prosódia; o professor que ironiza o aluno, que o minimiza, [...], tanto quanto o professor que se exime do cumprimento de seu dever de ensinar, de estar respeitosamente presente à experiência formadora do educando, transgride os princípios fundamentalmente éticos de nossa existência.

É preciso que o professor encoraje seu aluno a buscar o conhecimento e a ir além daquilo que ouve em sala de aula usando diferentes estratégias, recursos e parcerias em um trabalho multidisciplinar. Faz-se necessário que o professor pense na aprendizagem a partir do ponto de vista dos alunos, usando suas experiências para envolvê-los no processo de ensino, buscando despertar uma atitude crítica e orientar no processo de tomada de decisões, características que compõem o processo de aprender a aprender.

$\mathrm{Na}$ escola, uma das funções da biblioteca é de auxiliar o professor em seu trabalho e ampliar os conhecimentos vistos em sala de aula, bem como incentivar o gosto pela da leitura, pela pesquisa. Nesse contexto, o professor e o bibliotecário influenciam diretamente o 
estudante, por isso é necessário que esses dois profissionais trabalhem em conjunto, de maneira colaborativa, para auxiliar um ou outro na formação integral dos cidadãos.

Campello (2009) afirma que o tipo de colaboração exercida pelo bibliotecário depende do seu grau de intervenção no processo de ensino e aprendizagem. É preciso que o bibliotecário passe a exercer um papel mais efetivo na escola e procure cumprir a sua função educativa de forma adequada, trabalhando junto aos professores buscando oferecer apoio aos seus trabalhos em sala de aula, para que dessa forma consiga ganhar espaço na comunidade escolar. Todavia, esse processo colaborativo nem sempre é fácil, uma vez que a visão do bibliotecário como educador pode não existir na maioria das escolas, o que dificulta sua atuação. Dudziak (2001, p. 115) afirma que:

Inserir o bibliotecário na comunidade educacional nem sempre é fácil. Embora muitos bibliotecários se considerem educadores e possuam status para tal, nem sempre as escolas e faculdades às quais estão vinculados percebem esses profissionais como colegas engajados no processo educacional. Em geral, admite-se que as coleções das bibliotecas são essenciais para a formação do estudante, mas a necessidade de se educar para ter o "domínio da informação" fica muitas vezes em segundo plano.

Outro grande problema está na resistência dos professores em trabalharem com os bibliotecários, talvez por medo de saírem de suas zonas de conforto ao se abrirem para uma forma diferente de ensino e aprendizagem e que lhes exija uma nova maneira de pensar e trabalhar. Campello (2009, p. 58) salienta que:

Há também o fator competitivo quando o professor, trabalhando em projetos que envolvam a biblioteca, quer total autonomia, o que dificulta a colaboração. Em alguns casos, os professores veem os bibliotecários como um risco, uma ameaça de mudança que o uso da biblioteca pode representar em sua pratica pedagógica.

A colaboração entre bibliotecários e professores é de extrema importância e deve ser buscada com afinco, uma vez que ela irá cooperar para formar nos alunos o hábito de usar a informação, de pesquisar e utilizar a biblioteca de forma crítica.

Em sala de aula o professor necessita ser uma pessoa questionadora e instigante, muito mais do que trabalhar com o certo e com o errado, o professor precisa entender o porquê da resposta do aluno, qual o pensamento o levou até lá porque é o caminho que conta. É fundamental que professor e aluno andem juntos, buscando diferentes meios de resolver determinados problemas.

Muito mais que um ensino mecanizado, o professor deve ajudar a interpretar ideias e assim não estará limitando ao aluno ou minando a sua curiosidade, mas estará orientando e 
O trabalho cooperativo entre bibliotecários e professores para o desenvolvimento da competência em informação: criação de um programa voltado para alunos do ensino médio

auxiliando o educando em sua busca pelo saber. Dessa forma, o professor estará cooperando para a criação de uma aprendizagem significativa.

É preciso que o professor entenda e respeite o aluno e a experiência que ele carrega afinal seu modo de pensar e entender o mundo vai afetar diretamente sua forma de aprender. Freire (2013) defende que o respeito à autonomia e à dignidade de cada um é uma questão de ética e não um favor a ser concedido. É nesse sentido que o professor autoritário afoga a liberdade do educando, amesquinhando o seu direito de estar sendo curioso e inquieto.

O bibliotecário deve ser um colaborador, indo além das paredes das bibliotecas, fazendo-se presente em sala de aula e mostrando ao professor que pode auxiliá-lo no processo de ensino também. Neste contexto, Silva (2004, p. 15) fala que:

O professor muitas vezes sobrecarregado de tarefas, opta pelo confinamento, acomoda-se e evita procurar outras possibilidades para enriquecer sua prática e sua performance em sala de aula. Convencido de que não poderia encontrar nada de muito interessante numa biblioteca escolar que o auxiliasse realmente ele distancia-se desta.

Cabe ao bibliotecário escolar fazer valer o seu espaço e mostrar-se presente, tanto para o professor como para o aluno. É preciso que se engajem no processo de ensino, para serem capazes de auxiliarem na formação de estudantes competentes informacionalmente. Dudziak (2001, p. 119) salienta que:

Devido à própria cultura do docente, o bibliotecário é visto como aquele que dá suporte ao ensino, mas não está diretamente envolvido com as praticas pedagógicas e assim deve permanecer para não sobrecarregar ainda mais o currículo. Os bibliotecários, por sua vez, muitas vezes não querem abandonar sua passividade. Entretanto, quando querem atuar mais diretamente junto à comunidade educacional, por dever e por desejo profissional, sentem-se muitas vezes excluídos e menosprezados em suas iniciativas e não sabem como alterar esta situação.

É preciso ter em mente que a biblioteca escolar serve para atender a todos os usuários, e isso não inclui somente os alunos, mas também engloba os professores, e é nesse ponto que o bibliotecário deve investir. Ele deve mostrar que é capaz de ajudar e ser participante do processo de ensino e aprendizagem, pois possui as ferramentas necessárias para ajudar na sala de aula.

O bibliotecário escolar possui um papel educador muito importante, pois seu trabalho está diretamente ligado à informação, tecnologias e processos de busca. Ele está capacitado a auxiliar tanto o professor quanto o aluno, no processo de formação de cidadãos competentes em informação.

Entretanto, é preciso que barreiras sejam quebradas e que trabalhos colaborativos entre professores e bibliotecários sejam feitos, sempre em prol de oferecer o aluno o melhor respaldo 
Ane Fonseca e Daniela Spudeit

possível para oportunizar sua aprendizagem de modo significativo. A atuação conjunta desses dois profissionais é de extrema importância para a criação de pensadores críticos e atuantes na sociedade.

A informação está em toda parte e muda a cada instante, fazendo com que seja necessário o desenvolvimento de habilidades específicas para lidar com ela, as chamadas competências informacionais. Na educação, a formação de alunos com essas competências está diretamente ligada com o trabalho a ser desenvolvido pelo professor em sala de aula e pelo bibliotecário. A pré-disposição desses dois profissionais em trabalhar em conjunto, será um fator determinante para o desenvolvimento de competências informacionais em seus alunos, possibilitando a formação de um cidadão, crítico, reflexivo, participante e preocupado com a sociedade em que vive.

\section{Competência em Informação: histórico e atualidade}

Na sociedade contemporânea, a informação é vista como um fragmento precioso para a vida das pessoas. Contudo, o grande fluxo de notícias, dados e informações confunde a população, que fica sem saber como orientar-se em meio ao caos informacional.

\footnotetext{
O que é verdade hoje é frequentemente desatualizado amanhã. Um bom trabalho hoje pode ser obsoleto no próximo ano. Para promover a independência e qualidade de existência econômica, há uma necessidade ao longo da vida para ser informado e upto-date. (AMERICAN LIBRARY ASSOCIATION, tradução da autora, 1989).
}

A dificuldade está justamente na maneira de lidar com todo esse amontoado de informações. Saber a forma correta de filtrar o que é ou não é relevante tornou-se uma tarefa difícil. Uma vez que é preciso investigar a fonte original da informação para podermos julgar sua validade, entretanto a maioria das pessoas parece não saber como fazer isso.

Dudziak (2001) afirma que do grande fluxo de informação disponibilizada surge o paradoxo do não acesso a informação. A explosão informacional criou barreiras ao acesso, seja pelo custo da busca pela informação, seja pela ignorância a respeito das novas ferramentas informacionais disponíveis e a habilidade em lidar com elas. A existência dessas barreiras apresenta a necessidade de instruir o ser humano a compreender:

É nesse contexto que os estudos sobre a Competência em Informação ganham enfoque. Segundo Gasque (2012, p. 28) competência em informação "corresponde ao processo de desenvolvimento de competências para localizar, selecionar, acessar, organizar e usar 
O trabalho cooperativo entre bibliotecários e professores para o desenvolvimento da competência em informação: criação de um programa voltado para alunos do ensino médio

informação e gerar conhecimento visando à tomada de decisões e à resolução de problemas". Com isso é possível dizer que as pessoas competentes em informação são aquelas capazes de localizar e aplicar o conhecimento de maneira eficiente e eficaz.

Competência em informação é a tradução mais usada por pesquisadores brasileiros quando se referem à information literacy. Dudziak (2003, p. 23) explica que "enquanto conceito permanece um tanto indefinida, como uma metáfora bem construída, carregada de conotações, nem sempre bem vista ou entendida”. Entretanto, apesar da nebulosidade de seu conceito, a information literacy tem sua gênese na necessidade de lidar com o universo informacional da atualidade.

De acordo com Campello (2006) o termo information literacy foi citado pela primeira vez nos Estados Unidos, por Paul Zurkowski, na década de 70 para se referir as competências necessárias ao uso de fontes eletrônicas, onde se definia a necessidade de se ensinar as pessoas a como utilizar de maneira correta esses produtos (CAMPELLO, 2006).

Todavia, em 1976, o termo surge com uma maior abrangência, sendo relacionado com uma série de habilidades relacionadas à resolução de problemas e tomadas de decisões. Assim sendo, muito alem de localizar a informação, torna-se necessário saber como usá-la de maneira a tomar decisões corretamente. Dudziak (2003, p. 24) salienta que em 1976:

Um novo significado de information literacy surgiu: dois autores (Hamelink e Owens)
anteviram a information literacy (IL) como um instrumento de emancipação política.
Nesse momento, a inserção do conceito no contexto da cidadania elevou a IL a um
novo patamar, pois esta ia além da simples aquisição de habilidades e conhecimentos
ligados à informação. Incluía-se agora a noção dos valores ligados à informação para
a cidadania.

Assim sendo, a information literacy deixa de ter destaque como um movimento em busca de habilidades técnicas, para tornar-se uma ação de cunho político-social, tendo por base a premissa que cidadãos bem informados e capacitados para o uso da informação conseguem tomar decisões mais inteligentes e condizentes com suas responsabilidades para com a sociedade.

Campello (2006) explica que ainda na década de 80, a classe bibliotecária se apropria do termo Information Literacy para poder expressar a contribuição da biblioteca na aprendizagem, principalmente no que dizia respeito às habilidades de pesquisa e uso das fontes de informação. A information literacy passa, então, a ser estudada como uma ferramenta a ser utilizada para a contribuição da aprendizagem, a fim de auxiliar o indivíduo na pesquisa e na validação da informação obtida. 
Dudziak (2003) também enfatiza que, ainda na década de 80, foram publicados dois documentos de extrema importância para a information literacy, são eles: o livro editado por Patrícia S. Breivik e E. Gordon Gee intitulado "Information Literacy: Revolution in the Library”, que enfatiza a cooperação entre bibliotecários e administradores das universidades, e o relatório publicado pela American Library Association (ALA) intitulado "Presential Committe on Information Literancy: Final Report", onde se ressalta a importância da information literacy para indivíduos, trabalhadores e cidadãos e onde se recomenda um novo conceito de ensino-aprendizagem, com a diminuição da lacuna entre sala de aula e biblioteca. Para a autora, esses dois documentos enfocam o papel educacional das bibliotecas e a importância dos programas de information literacy. O documento publicado pela ALA define que:

Para ser competente em informação a pessoa deve ser capaz de reconhecer quando precisa da informação e possuir habilidades para localizar, avaliar, e usar efetivamente a informação [...], ou seja, as pessoas competentes informacionalmente são aquelas que aprenderam a aprender. Essas pessoas sabem como aprender porque sabem a informação está organizada, como encontrar a informação, de tal forma que os outros possam aprender com ela. (AMERICAN LIBRARY ASSOCIATION, tradução da autora, 1989).

De acordo com Dudziak (2003), a partir da definição dada pela ALA, nos anos 90 surgiram vários programas educacionais ao redor do mundo, todos voltados para a information literacy e objetivando transformar os usuários em aprendizes independentes, enfatizando a integração curricular e a cooperação da comunidade.

No Brasil, segundo Dudziak (2003), entre os precursores da Information Literacy estão os bibliotecários que começaram a utilizar o termo para se referirem ao desenvolvimento de estudos relativos à educação de usuários. Foi Caregnato (2000) quem primeiro traduziu o termo information literacy usando a expressão habilidade informacional em um artigo cujo objetivo era discutir a educação de usuários e as formas de desenvolver habilidades informacionais.

Desde então, muitas foram às expressões utilizadas para traduzir o termo Information Literacy no Brasil. Segundo Gasque (2010), a partir de 2000, no Brasil, foram publicados muitos artigos e pesquisas que utilizaram expressões como 'Letramento Informacional; 'Alfabetização Informacional'; 'Habilidade Informacional' e 'Competência Informacional'. Entretanto, de acordo com a autora, nos últimos anos a expressão Information literacy, no Brasil, tem sido traduzida como 'Competência Informacional' por grande parte dos pesquisadores. 
O trabalho cooperativo entre bibliotecários e professores para o desenvolvimento da competência em informação: criação de um programa voltado para alunos do ensino médio

Apesar de serem muitas as nomenclaturas usadas para construir o conceito do que seria a "capacidade essencial, necessária aos cidadãos para se adaptar à cultura digital, à globalização e à emergente sociedade do conhecimento" (CAMPELLO, 2009, p. 12), nesse trabalho será adotado o termo Competência em Informação, pois visa designar o conjunto de habilidades que se fazem necessárias para viver em uma sociedade caracterizada pelo ambiente informacional complexo de acordo com Campello (2006).

O ser competente está ligado à habilidade de tornar-se capaz de aprender de maneira autônoma ao longo da vida, ser alguém capaz de analisar determinado acontecimento, pesquisar sua fonte e formar uma opinião baseada em seu próprio pensamento crítico.

Desta forma, Belluzzo, Kobayashi e Feres (2004) entendem que a competência em informação se inicia se estende na aprendizagem ao longo da vida por meio de uma série de habilidades que podem incluir o uso de tecnologias, assim como um conjunto de habilidades inegavelmente ligadas ao aprendizado e à capacidade de criar significado a partir da informação, sendo uma condição indispensável, que as pessoas saibam "aprender a aprender" e realizem o "aprendizado ao longo da vida", tendo em vista a necessidade da construção do conhecimento e a intervenção na realidade social.

Dudziak (2003, p. 28) ao tratar a competência como um aprendizado ao longo da vida, vai defini-lo como "O processo contínuo de internalização de fundamentos conceituais, atitudinais, e habilidades necessárias a compreensão e interação permanente com o universo informacional e sua dinâmica, de modo a proporcionar um aprendizado ao longo da vida. ”

Portanto, pode-se entender que o processo de buscar e localizar a informação de qualidade é de extrema importância. Contudo, somente isso não é o bastante, é preciso que o indivíduo saiba o que fazer com a informação, ela sozinha é algo isolado, mas ao conectá-la com outras informações é possível produzir conhecimento. Segundo Trindade (2002, apud BELLUZZO, 2005, p. 9) as principais competências na formação de uma pessoa ao longo da vida são:

- A representação: capacidade de reproduzir determinados fatos ou acontecimentos mediantes imagens ou símbolos;

- A retenção: armazenar e/ou conservar dados no sistema cognitivo;

- A recuperação: capacidade de elaboração tendo em vista a reinteração da informação armazenada na memória;

- A interpretação: atribuição de significado pessoal a um fato ou acontecimento; 
- A interferência: capacidade de completar uma informação parcial ou a partir de pressupostos que não tem suficiente força probatória;

- A transferência: aplicação dos processos cognitivos adquiridos na realização de uma tarefa à outras tarefas diferentes;

- A avaliação: atribuir um valor a comparação entre a medida de um fenômeno ou comportamento e um critério.

Nesse processo, a escola acaba por torna-se um elemento de fundamental importância, pois ela pode possibilitar ao aluno as ferramentas necessárias e os profissionais capazes de auxiliá-lo no processo de aprendizagem que o levará a tornasse um cidadão competente informacionalmente.

Dudziak (2001) salienta que a visão educacional tradicionalista está sofrendo grandes transformações e que o conceito do professor transmissor de um conjunto fixo de informações ao estudante, está sendo substituído por um enfoque educacional que seja voltado para os processos de construção e disseminação do conhecimento, com enfoque, no "aprender a aprender" e na educação continuada, onde a informação é o principal elemento.

A visão de ensino em que professor e bibliotecário trabalham em conjunto só tem a favorecer o aluno, a escola que incentiva a criança a procurar e trabalhar com a informação e transformá-la em conhecimento está auxiliando, não somente a um futuro adulto, mas também está colaborando para a criação de uma sociedade mais digna e igualitária.

Ao entrar na escola, a criança deve passar pelos diferentes estágios de uso da informação, começando pela alfabetização informacional, passando pelo letramento informacional, adquirindo por fim a competência em informação. Sua aprendizagem terá sido evolutiva e com um objetivo claro de que o educando, torne-se um adulto consciente.

Dessa forma, é possível entender que o aluno vai formar seu conhecimento com base nas experiências que carrega e que vai usar as varias fontes de informação que estão disponíveis, diferentemente do ensino tradicional onde o detentor do conhecimento é única e exclusivamente o professor. Nesse ambiente, construtivista, os orientadores, professor e bibliotecário, assumem o papel de facilitadores e ajudam ao aluno a orientar-se nesse universo complexo de informações.

Esse processo de utilização das experiências, ao adquirir a informação e criação de conhecimento pode ser chamado de Aprendizagem Significativa, ou seja, mais do que simplesmente receber a informação, a criança atribui um significado a ele, e isso permite a construção do conhecimento, como mencionado anteriormente. 
O trabalho cooperativo entre bibliotecários e professores para o desenvolvimento da competência em informação: criação de um programa voltado para alunos do ensino médio

É possível entender que ser um indivíduo possuidor de competência em informação é algo essencial na presente sociedade, pois sem tal característica as pessoas correm o risco de serem sufocadas ou manipuladas pelo crescente número informações. Contudo, para que seja possível esse olhar crítico capaz de atuar socialmente, de questionar, de buscar um mundo melhor, é preciso que o processo de mudança comece na escola.

É necessário que professores e bibliotecários comecem o processo de desenvolvimento da competência em informação nos alunos já no ensino infantil, pois assim a aprendizagem será algo natural e poderá, enfim, adentrar na verdadeira Sociedade do Conhecimento, ou seja, uma sociedade baseada na construção do conhecimento e possuidora de cidadãos capacitados para o pensamento analítico e reflexivo.

As mudanças ocorridas na sociedade atual trouxeram novos paradigmas, novas formas de pensamento e uma valorização cada vez maior da informação. O mundo globalizado despertou a necessidade de uma consciência digital, e da preciosidade do conhecimento como um bem de valor. O relatório da ALA (1989) afirma que:

Nenhuma outra mudança na sociedade [...] ofereceu desafios maiores do que o surgimento da era da informação. A informação está se expandindo a um ritmo sem precedentes e avanços enormemente rápidos estão sendo feitos na tecnologia para armazenar, organizar e acessar a crescente onda de informações. (Tradução da autora).

Por essa razão, se faz necessário a discussão sobre a Competência em Informação e as metodologias que podem ser utilizadas para seu desenvolvimento, uma vez que, de acordo com Gasque (2010, p. 86), ao ser competente informacionalmente, o indivíduo possuirá as habilidades necessárias para:

- Determinar a extensão das informações necessárias;

- Acessar a informação de forma efetiva e eficiente;

- Avaliar criticamente a informação e suas fontes;

- Incorporar a nova informação ao conhecimento prévio;

- Usar a informação de forma efetiva para atingir objetivos específicos;

- Compreender os aspectos econômicos, legal e social do uso da informação, bem como acessá-la e usá-la ética e legalmente.

Portanto, quando se fala em competência em informação no ambiente escolar, é de fundamental importância que se pense em atividades e ferramentas que auxiliam no desenvolvimento da competência em informação, principalmente no que tange à pesquisa 
Ane Fonseca e Daniela Spudeit

escolar, já que esta é uma "das principais atividades realizadas no processo de ensino e aprendizagem desde as séries iniciais" (BELLUZZO, 2008, p. 12).

Assim sendo, foram criados modelos de aplicação de programas de competência em informação, a fim de auxiliarem no processo de ensino-aprendizagem e na busca e uso de informação.

Um desses modelos chama-se Information Search Process (ISP) foi desenvolvido por Carol Kuhlthau. É um modelo de seis estágios (início, seleção, exploração, formulação, coleta e apresentação) que compõe o processo de busca da informação, propondo autonomia durante a pesquisa. Esse modelo procura descrever a experiência dos usuários no processo de busca da informação como uma série de pensamentos, sentimentos e ações (KUHLTHAU, tradução da autora, 2004).

Outro modelo de programa de aplicação de competência em informação é o criado por Belluzzo, esse modelo está baseado na aprendizagem significativa e faz uso dos mapas conceituais. Nomeado como diagrama Belluzzo, ele possui o objetivo de definir e reconhecer a necessidade de informação, o foco central de interesse e os conceitos envolvidos de forma hierárquica.

Como pode ser visto nos modelos citados acima, a ideia de competências em informação, está intimamente ligada ao individuo e aos conhecimentos, emoções e ideais que ele trás dentro de si. Quando em ambiente escolar, o ensino e o trato da informação precisam ser abordados de maneira a ser entendida no sentido amplo e que atenda as exigências da sociedade, permitindo a formação de um cidadão crítico e reflexivo.

Dessa forma, o presente trabalho buscou conhecer a realidade de uma instituição escolar pública para verificar como ocorria o planejamento das atividades realizadas pela biblioteca na escola e propor um programa para desenvolvimento da competência em informação com ações e indicadores de avaliação de acordo com o contexto dessa escola conforme será apresentado a seguir. 
O trabalho cooperativo entre bibliotecários e professores para o desenvolvimento da competência em informação: criação de um programa voltado para alunos do ensino médio

\section{Apresentação e análise dos resultados}

O Colégio Pedro II foi fundado em 02 de dezembro de 1837, sendo oficializado em 20 de dezembro desse mesmo ano, como decorrência da reorganização do Seminário São Joaquim, sendo batizado em homenagem ao imperador-menino. Sua primeira unidade foi instalada no centro do Rio de Janeiro e funciona ate os dias de hoje. No total, o Colégio Pedro II possui 14 unidades funcionando, além da unidade de educação infantil de Realengo I, que é vinculada à Pró-Reitoria de Ensino. A missão do colégio consciente em educar crianças e adolescentes, tornando-os capazes de responder às transformações técnicas, culturais, emocionais e sociais do mundo de hoje. Sua proposta pedagógica consiste:

\footnotetext{
No conhecimento conceitual, com um enfoque interdisciplinar e contextualizado, para formar competências cognitivas e de cidadania, foi construída firmando-se em alguns pressupostos metodológicos colocados pelos docentes nas reuniões de discussão do Projeto, nas reuniões departamentais e nos Grupos de Trabalho para sua elaboração. (BRASIL, 2001, p. 84)
}

Sobre a estrutura e organização das bibliotecas do Colégio Pedro II, pode-se citar o art. $3^{\text {o }}$ da Portaria $N^{\circ} 2810$ de 01 de abril de 2014, que para fins de padronização técnica e metodológica, a seção de bibliotecas se subdivide em:

I. Salas de Leitura;

II. Bibliotecas Escolares

III. Biblioteca da Pró-Reitoria de Pós-Graduação, Pesquisa, Extensão e Cultura;

IV. Núcleo de Documentação e Memória (NUDOM);

V. Biblioteca Histórica;

VI. Mediateca Jean-Luc Lagardède;

VII. Mediateca de Inglês;

VIII. Centro de Estudos Filológicos Antenor de Veras Nascentes;

IX. Demais bibliotecas, salas de leitura e ambientes destinados a atividades informacionais de caráter educacional e científico. (BRASIL, 2014).

$\mathrm{O}$ art. $4^{\circ}$, da mesma portaria, vai instituir que a seção de Biblioteca e Salas de leitura será coordenada por um bibliotecário (a) com as seguintes atribuições:

I. Fixar os princípios de funcionamento das bibliotecas, salas de leitura, mediatecas e outros espaços de sua responsabilidade de acordo com o Projeto de Desenvolvimento Educacional e o Projeto Institucional do Colégio Pedro II; 
II. Estabelecer as normas a serem adotadas no processamento técnico dos acervos contidos nos espaços informacionais citados no Art. $3^{\circ}$ desta portaria;

III. Supervisionar as atividades desenvolvidas pelos servidores lotados nos espaços informacionais citados no $3^{\circ}$ desta portaria;

IV. Acompanhar o planejamento da planta física e infraestrutura dos espaços informacionais citados no $3^{\circ}$ desta portaria;

V. Elaborar as normas para o funcionamento dos espaços sob sua responsabilidade;

VI. Manter reuniões periódicas a fim de deliberar sobre assuntos técnicos, administrativos e pedagógicos relativos a sua área de atuação. (BRASIL, 2014).

A unidade escolhida para a pesquisa foi a Unidade de Duque de Caxias, inaugurada em 2007, a princípio, oferecia à comunidade apenas o curso de Educação Profissional Técnica de Nível Médio Subsequente ao Ensino Médio - área de formação Informática. No ano seguinte, a unidade foi transferida para a Avenida Presidente Kennedy, no centro de Duque de Caxias, e começou a ofertar também o Ensino Médio Regular. Em 2012, foi inaugurado o novo campus, no bairro Centenário, oferecendo cursos do Ensino Médio Regular e do Programa Nacional de Acesso ao Ensino Técnico e Emprego (Pronatec), no $3^{\circ}$ turno. (COLÉGIO PEDRO II, 2011)

A escolha da escola foi feita com base no trabalho desenvolvido pelo bibliotecário dessa unidade juntamente com o diretor pedagógico da unidade, buscando-se analisar essa parceria. Moro e Estabel (2003, p. 2) afirmam que "quando os alunos descobrem a importância da biblioteca escolar, esta passa a ser o ambiente propício para a aprendizagem e a construção do saber". Mais do que somente atender a necessidade momentânea do aluno, a biblioteca escolar tem a função de prepará-los para o mundo que existe fora dos muros da escola.

Portanto, a contribuição da biblioteca não se restringe somente ao ambiente escolar, uma vez que ela, além de ser um local para o desenvolvimento da aprendizagem, a biblioteca é, também, um lugar de preparação para a vida em sociedade, uma vez que os ensinamentos aprendidos devem auxiliar o aluno ao longo de sua vida. Então, a biblioteca escolar deve buscar a interação entre seus usuários e promover a leitura, a fim de auxiliar na formação de um cidadão crítico. É possível perceber isso na entrevista com o bibliotecário do Colégio Pedro II - Campus Duque de Caxias

Para o aluno, a nossa preocupação é de prepara-lós não só para os exames nacionais, mas para a rotina deles de pesquisa. Torna-los críticos. Assim aqui a gente tem essa vontade de torna-lós críticos na pesquisa, nos livros que nós temos... então a biblioteca escolar aqui tem esse objetivo de prepara-los não só para o ambiente escolar, mas para fora também. Até porque o nosso campus está localizado bem em 
O trabalho cooperativo entre bibliotecários e professores para o desenvolvimento da competência em informação: criação de um programa voltado para alunos do ensino médio

Caxias, uma parte que é muito carente de bibliotecas, tanto escolares quanto públicas, acho que em Caxias só tem uma biblioteca publica, e a nossa biblioteca ela é aberta para o público da comunidade também, então alunos de outras escolas podem vir aqui, podem pesquisar o nosso material e consultar o nosso acervo. Porque nós vimos à necessidade de bibliotecas escolares.

Todavia, para que uma biblioteca possa fazer a diferença no contexto escolar, é preciso que ela supere os vários desafios que se apresentam. Além dos recursos e investimentos necessários, outra dificuldade que existe, é o apoio da direção e demais professores da escola. O bibliotecário do Colégio Pedro II coloca que:

O maior desafio da biblioteca escolar é ter o apoio da coordenação pedagógica e ter recursos para colocar os seus desejos em prática, recursos que eu falo é de espaço, financeiro e humano também, ou seja, funcionários que possam trabalhar com você. Ter o apoio do coordenador pedagógico é fundamental, dos professores também.

Mais uma vez é possível perceber que a realização do trabalho em conjunto é de extrema importância para o desenvolvimento do trabalho realizado pela biblioteca escolar junto aos alunos. A participação dos professores e da direção pedagógica nas atividades realizadas pela biblioteca torna-se um incentivo para que os próprios alunos se envolvam com as programações oferecidas. De acordo com Moro e Estabel (2003), professores, bibliotecários e pedagogos devem trabalhar em conjunto, não permitindo que o trabalho da biblioteca se torne isolado. Para as autoras, é fundamental que exista uma relação de colaboração e cooperação e é essa relação que permitirá que a biblioteca seja o coração da escola. No Colégio Pedro II - Campus Duque de Caxias isso ocorre e fica muito claro no depoimento do diretor pedagógico ao defender esse ponto de vista:

O trabalho dos três (biblioteca escolar, professor e direção pedagógica) se complementa na transformação do aluno, Eles devem promover o acesso à cultura, deixando o usuário com uma visão mais ampla e devem fazer com que ele entenda melhor a sociedade em que vivemos.

Portanto, para que a biblioteca escolar possa se tornar um "importante instrumento no apoio didático pedagógico" (MORO, ESTABEL, 2011, p. 13). É necessário que a equipe da biblioteca participe das reuniões pedagógicas e gerenciais da escola, para que o planejamento da biblioteca ocorra em concordância com o planejamento escolar.

Segundo Campello (2009) a necessidade de entrosamento entre a biblioteca e a escola é reforçada, assim sendo o trabalho do bibliotecário deve estar em consonância com a sala de aula e interagir de modo harmonioso com o corpo docente. Essa colaboração é a responsável pelo êxito da biblioteca como recurso de aprendizagem. 
Ane Fonseca e Daniela Spudeit

A participação dos alunos nos processos que envolvem a biblioteca e que determinam as escolhas dos livros que vão acervo e das atividades, também, é de extrema importância, pois trata-se de uma forma incentivar ao aluno a frequentar e participar do ambiente da biblioteca.

Assim sendo, colher a opinião dos alunos, realizar questionários e observar seu comportamento são práticas que devem ser comuns nas bibliotecas. Desta forma, o bibliotecário explica que:

\begin{abstract}
Com os alunos são feitas lista de sugestões, pedindo dicas, quais livros eles acham interessantes pra biblioteca... Nós criamos no Google docs, um link facilzinho de preencher e mandamos para todos os alunos cadastrados na biblioteca. Eles colocam: Olha eu quero o livro do Percy Jackson, por exemplo. Já é um material que a gente separa para aquisição. E aqui, como a biblioteca é pequena eu vi a necessidade de estar sempre próximo e não isolado, tipo ficar numa caixinha separada com os auxiliares, onde o aluno não tem contato comigo, não! Eu que ter esse contato com o aluno, para interagir com ele. Então a gente faz essa... é muito da observação do que ele precisa. "Há eu queria tanto ler livro tal, como é que eu faço pra achar? Onde eu consigo?" às vezes a gente não tem aqui. Já teve casos, só que mais pontuais, da gente indicar a Estante Virtual, Biblioteca Nacional... muita coisa de observação.
\end{abstract}

Todavia, para que os usuários da biblioteca escolar tenham liberdade de escolha e participação nas decisões e planejamento da mesma, é necessário que o bibliotecário escolar realize atividades que permitam a interação dos alunos com o ambiente, para que eles entendam como a biblioteca funciona e qual a sua função no ambiente escolar.

De acordo com Maroto (2012), para que os frequentadores da biblioteca escolar tenham voz nos planejamentos realizados para a mesma, é preciso que se promovam atividades que propiciem momentos e espaços de envolvimento, e de crescimento e de conquista desses direitos, e dessa participação, ou seja, é necessário que a biblioteca seja um espaço democrático, de promoção da leitura, de discussão, e de difusão e socialização de experiências.

O bibliotecário pontua as atividades realizadas pela biblioteca na unidade de Duque de Caxias pontuando que são realizadas em parceria com os professores e também visando desenvolver algumas habilidades relacionadas às competências informacionais, tais como:

- Cine+Biblio: Foi uma ideia do Diretor pedagógico, está na sua $5^{\circ}$ ou $6^{a}$ edição e possui duas seções (manhã e tarde). Em cada edição um professor é convidado para debater com os alunos e mostrar os pontos que o filme tem em relação com a sua matéria ou com as outras disciplinas. Os livros e outros materiais que a biblioteca possui e que sejam relacionados ao filme são divulgados e ficam expostos para os alunos, para que eles façam esse link de pesquisa. Ex: Filme Lincoln - Livros da Guerra da Secessão. No filme "O Labirinto do Fauno" a professora convidada fez vários links com livros que a biblioteca possuía. O objetivo é passar o filme, ter o debate, mostrar a utilização dessa ferramenta (filme) para a pesquisa. Mostrar e divulgar o material existente na biblioteca. Atualmente o grêmio estudantil é o 
O trabalho cooperativo entre bibliotecários e professores para o desenvolvimento da competência em informação: criação de um programa voltado para alunos do ensino médio

responsável pela escolha do filme, eles fazem uma votação entre os alunos e escolhem qual o filme mais interessante. Depois dessa escolha a biblioteca começa a trabalhar.

- Sessão de Concursos: Bibliografias dos concursos do ENEM e da UERJ - É feito um levantamento de todos os artigos que caíram nas provas (copilação de uma apostila). Esse levantamento apresenta ao aluno como a pesquisa foi feita, como começou e quais as fontes consultadas. $O$ objetivo é ensinar o aluno como pesquisar e como recuperar esses artigos. Orientar a pesquisa deles através das nossas práticas.

- Livro Além das Paginas (Exposição para o próximo semestre): Mostra a importância do livro para os outros gêneros. O objetivo é atrair o aluno para a leitura. Apresenta: Livros que inspiraram músicas, livros adaptados para o cinema, livros adaptados para o teatro, $H Q$ 's que viraram filmes, filmes adaptados para quadrinhos e livros que serviram de inspiração para novelas e séries de televisão.

É possível perceber que, as atividades desenvolvidas pela biblioteca do Colégio Pedro II possuem a intenção de dinamizar o ambiente e do possibilitar aos alunos a criação de links com diversos conteúdos do saber, procurando incentivar a pesquisa, auxiliar no uso das ferramentas de informação e o preparo para o mundo fora da escola, buscando ajudar os alunos a desenvolverem habilidades para lidar com as informações presentes no seu dia a dia.

A participação dos professores nessas atividades, também, apresenta uma visão ampla do processo de aprendizagem, procurando o incentivar o trabalho cooperativo em prol da educação dos alunos. O professor tem a função de auxiliar o aluno tanto dentro quanto fora da aula e por essa razão, seu diálogo com o bibliotecário é tão importante, pois o professor, é um dos principais incentivadores dos alunos. Uma parte muito importante na construção do significado de uma biblioteca escolar está nas mãos dos mestres presentes em sala de aula. Corroborando com isso, o diretor pedagógico da escola analisada defende que:

Quando eu trabalhava em sala de aula eu não me comunicava com o bibliotecário. Hoje esse trabalho é feito em conjunto para a ampliação e divulgação do acervo, estimulando a leitura e a realização de projetos pedagógicos e culturais, como, por exemplo, o Cine+Biblio. Sim, incentivo os alunos e professores a procurarem a frequentarem a biblioteca.

Roca (2012) salienta que a função do professor é servir como um orientador ou guia, cujo trabalho é auxiliar no processo de construção que os alunos realizam com os significados coletivos culturalmente organizados. Assim sendo, para a autora, a construção do conhecimento deve ser concebida como um processo, onde o professor ajuda o aluno a construir significados e atribuir sentidos ao que se aprende.

Campello (2009) diz que a colaboração de professores e bibliotecários é uma necessidade de estrema importância, pois dela dependerá o sucesso da biblioteca como um 
ambiente de aprendizagem. Ainda segundo a autora essa colaboração torna-se ainda mais importante quando o bibliotecário desenvolve atividades com os estudantes.

Faz-se necessário, portanto, que os professores enxerguem esse novo mundo, composto por um fluxo cada vez maior de informação e que entendam que o ensino tradicional ou mecanizado já não funciona mais na sociedade atual. É preciso abrir-se para uma nova forma de ensino e para um trabalho colaborativo, portanto sua participação com o trabalho realizado pela biblioteca é de extrema importância, pois se torna um incentivo para o aluno procurar diferentes formas de obter a informação.

É de fundamental importância que a biblioteca escolar acompanhe os alunos, já que ela é a facilitadora num processo que conduz a uma forma de educação mais aberta e menos mecanizada, a fim de contribuir para o desenvolvimento de competências básicas a um cidadão ativo no contexto da Sociedade da Informação.

Portanto, baseando-se nas informações obtidas por meio das entrevistas realizadas, criou-se um programa de desenvolvimento de competência informacional a ser aplicado no Colégio Pedro II - Unidade de Duque de Caxias, a fim de sugerir atividades que auxiliem na formação de seus alunos como cidadãos, que preparem os mesmos para a vida fora da escola e que possibilitem a cooperação no trabalho entre professores, bibliotecários e direção pedagógica.

Pensando nas atividades que já são realizadas pela biblioteca e pela parceria que existe entre professores, diretor pedagógico e o bibliotecário na unidade Duque de Caxias do Colégio Pedro II, foi estruturado um programa voltado para o desenvolvimento de competências informacionais nos alunos do ensino médio. Na entrevista, percebeu-se que existem algumas ações realizadas de forma isoladas e não estruturadas, até porque a biblioteca é nova e o planejamento do trabalho está no início.

O Programa foi feito com base nas ideias de Kuhlthau (2013) e Gasque (2012) afim de que os conteúdos usados no programa e que envolvam a competência em informação sejam integrados aos ensinamentos dos professores em sala de aula. Uma vez que é imprescindível que a aprendizagem tenha sentido para os alunos. Por essa razão é de extrema importância que professores e bibliotecários planejem em conjunto as atividades a serem realizadas.

Por essa razão, a aplicação do programa de competência em informação foi proposta para as turmas do $1^{\circ}$ ano do Ensino Médio, pois se pretende que ao ingressarem no ensino 
O trabalho cooperativo entre bibliotecários e professores para o desenvolvimento da competência em informação: criação de um programa voltado para alunos do ensino médio

médio, os alunos passem a ter uma familiaridade maior com o universo da pesquisa, do uso da informação, as fontes de informação e as ferramentas para acessar as mesmas, a fim de preparálos para a vida acadêmica na universidade e do mercado de trabalho. Apresenta-se a seguir a proposta do programa de desenvolvimento de competência em informação.

\begin{tabular}{|c|c|}
\hline $\begin{array}{l}\text { Local para } \\
\text { aplicação }\end{array}$ & Colégio Pedro II - Unidade de Duque de Caxias \\
\hline $\begin{array}{l}\text { Caracterização do } \\
\text { local }\end{array}$ & $\begin{array}{l}\text { Instituição de abrangência federal e grande tradição, sem, no entanto, entender essa } \\
\text { tradição como conservadorismo, mas buscando enxergá-la como uma herança cultural, } \\
\text { sempre reelaborada, com o propósito de desenvolver projetos em nome de uma educação } \\
\text { pública gratuita e de qualidade. }\end{array}$ \\
\hline Público-alvo & Turmas do $1^{\circ}$ ano do Ensino Médio \\
\hline $\begin{array}{l}\text { Quantidade de } \\
\text { pessoas } \\
\text { favorecidas }\end{array}$ & Aproximadamente 100 alunos \\
\hline $\begin{array}{l}\text { Objetivo geral do } \\
\text { programa }\end{array}$ & $\begin{array}{l}\text { Contribuir na educação e na formação de alunos competentes informacionalmente e } \\
\text { capazes de desenvolver um pensamento reflexivo a fim de torná-los aptos para lidar com } \\
\text { as transformações da sociedade. }\end{array}$ \\
\hline $\begin{array}{l}\text { Objetivos } \\
\text { específicos das } \\
\text { atividades }\end{array}$ & $\begin{array}{l}\text { - Apresentar fontes de pesquisa através de diferentes ferramentas e mídias; } \\
\text { - Capacitar o aluno como pesquisador; } \\
\text { - } \quad \text { Promover a interação entre a equipe biblioteca e o corpo docente. }\end{array}$ \\
\hline Duração & $\begin{array}{l}\text { As atividades ocorrerão ao longo do ano letivo, sendo divididas em trimestres ( } 1 \text { trimestre } \\
\text { para cada atividade) e com um período de preparação de um mês e meio antes da data } \\
\text { prevista para realização da atividade. }\end{array}$ \\
\hline $\begin{array}{l}\text { Descrição do } \\
\text { Programa e } \\
\text { Indicadores de } \\
\text { Avaliação }\end{array}$ & $\begin{array}{l}\text { Com o objetivo de apresentar fontes de pesquisa através de diferentes ferramentas e } \\
\text { mídias pode ser desenvolvida a Feira de Cinema: } \\
\text { - Feira de Cinema: Será realizada a partir dos filmes exibidos no Cine+Biblio. Os } \\
\text { filmes são escolhidos pelos próprios alunos para torná-los parte do processo. } \\
\text { Propõe-se que a temática seja ampliada e que os resultados obtidos sejam } \\
\text { compartilhados com todo o ambiente escolar. A partir disso, o diretor pedagógico, } \\
\text { professor e o bibliotecário organizam as atividades que serão desenvolvidas a partir } \\
\text { da exibição dos filmes. } \\
\text { Dependendo do filme, pode envolver professores de Literatura, Geografia, História, } \\
\text { Artes, etc. para tornar o projeto multidisciplinar. } \\
\text { Indica-se o debate entre o professor e os alunos e a partir disso propõem-se a } \\
\text { elaboração e apresentação de trabalhos baseados nos filmes assistidos ou sua } \\
\text { contribuição para a história do cinema. Para isso, devem ser disponibilizadas } \\
\text { ferramentas variadas, como consulta a mídias sociais, fontes filmográficas, acervos } \\
\text { de áudios e vídeos para que os alunos conheçam esses recursos e aprendam a } \\
\text { pesquisar neles. } \\
\text { Espera-se que os alunos: } \\
\text { 1. Façam uso das ferramentas disponíveis na biblioteca e em sala de aula; } \\
\text { 2. Que entendam, usem, avaliem e selecionem fontes impressas, eletrônicas e } \\
\text { audiovisuais; } \\
\text { 3. Analisem e interpretem o que é ouvido e visto; } \\
\text { 4. Recordem, resumam, parafraseiem e complementem o que é ouvido e visto. } \\
\text { O Cine+Biblio vai ocorrer ao longo do ano e a Feira de Cinema deve acontecer no fim } \\
\text { do ano letivo para que os alunos tenham tempo de montar a apresentação e uma boa } \\
\text { quantidade de filmes para escolher como tema. Propõe-se que seja feita na quadra da } \\
\text { escola, com estandes para a exposição de trabalhos e a projeção de trechos dos filmes } \\
\text { trabalhados. } \\
\text { Indicadores de avaliação: Deve-se realizar uma avaliação qualitativa buscando definir } \\
\text { quais os resultados esperados durante a aquisição da competência informacional dos } \\
\text { estudantes envolvidos no processo. } \\
\text { Assim sendo indica-se a utilização dos seguintes indicadores: } \\
\text { Observação da atividade apresentada e desenvolvimento da ideia. Tendo em pauta a }\end{array}$ \\
\hline
\end{tabular}

Bibl. Esc. em R., Ribeirão Preto, v. 5, n. 1, p. 36-63, 2016. 


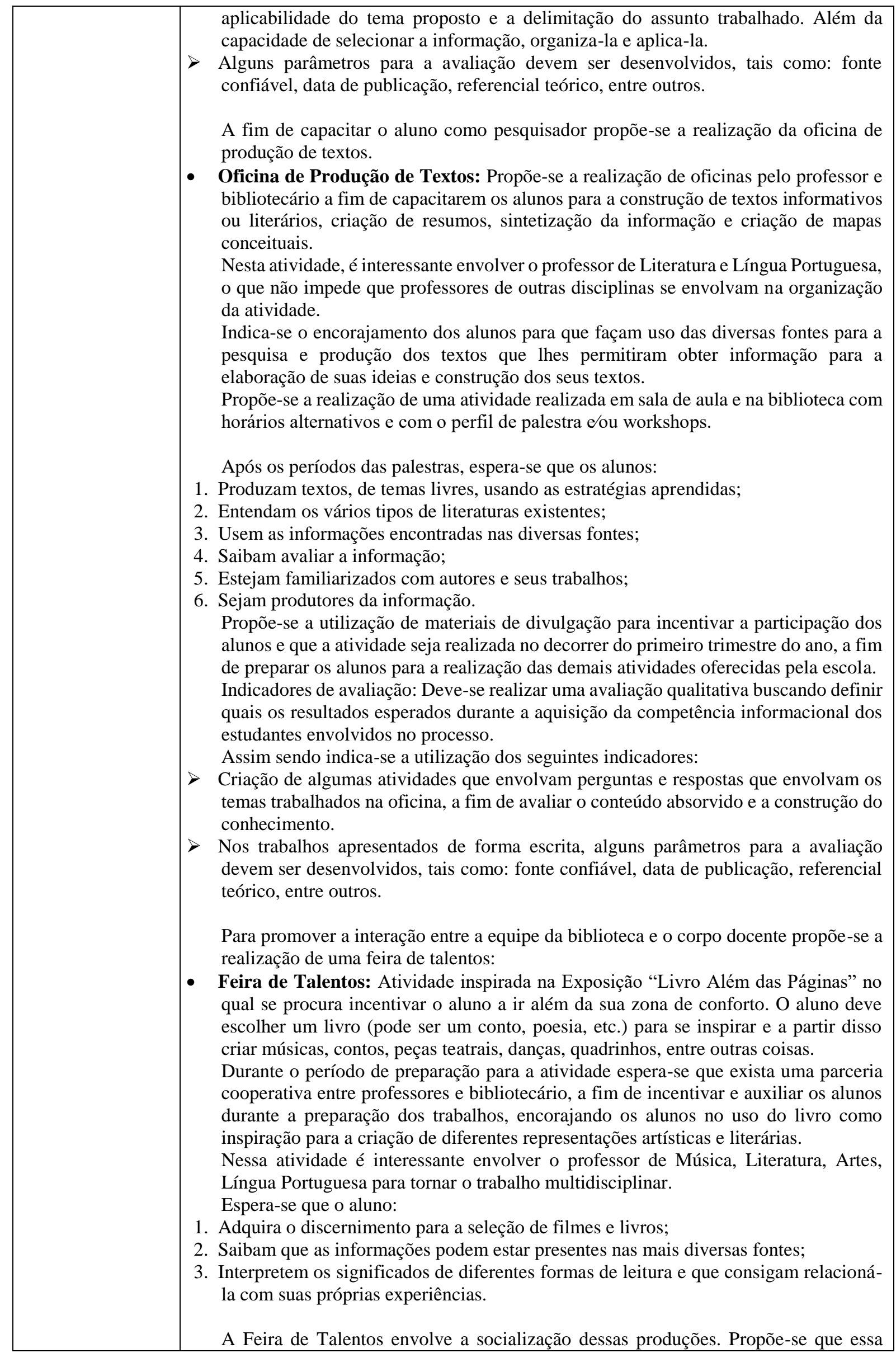

Bibl. Esc. em R., Ribeirão Preto, v. 5, n. 1, p. 36-63, 2016. 
O trabalho cooperativo entre bibliotecários e professores para o desenvolvimento da competência em informação: criação de um programa voltado para alunos do ensino médio

\begin{tabular}{|c|c|}
\hline & $\begin{array}{l}\text { atividade seja realizada no segundo trimestre do ano antes do período de férias e que } \\
\text { ocorra no auditório da escola para que exista um ambiente propício para a } \\
\text { apresentação de peças, músicas, etc. } \\
\text { Indicadores de avaliação: Deve-se realizar uma avaliação qualitativa buscando definir } \\
\text { quais os resultados esperados durante a aquisição da competência informacional dos } \\
\text { estudantes envolvidos no processo. } \\
\text { Assim sendo indica-se a utilização dos seguintes indicadores: } \\
\text { Observação da atividade apresentada, a fim de avaliar a aplicação dos conhecimentos } \\
\text { adquiridos, a coerência e a profundidade do trabalho e a agregação de conhecimentos } \\
\text { gerados individualmente. } \\
\text { Alguns parâmetros para a avaliação devem ser desenvolvidos, tais como: fonte } \\
\text { confiável, data de publicação, referencial teórico, entre outros. } \\
\text { Como descrito no público-alvo, essas atividades devem ser realizadas com as turmas do } \\
\text { primeiro ano do ensino médio com o objetivo de prepará-los para a pesquisa, para a } \\
\text { construção textual e para a utilização das ferramentas de pesquisa. } \\
\text { Recomenda-se que as atividades sejam desenvolvidas anualmente e em outros anos e } \\
\text { níveis, desde que sejam adaptadas para as demais turmas de acordo com o público-alvo. }\end{array}$ \\
\hline Recursos & $\begin{array}{l}\text { Recursos Humanos: Equipe da biblioteca; Professores (pelo menos dois com } \\
\text { participação direta na atividade), Colaboradores e direção pedagógica. } \\
\text { Recursos Estruturais: Quadra da escola, sala de aula, auditório da escola, equipamento } \\
\text { de som, multimídia e material de consulta para os alunos. } \\
\text { Recursos Financeiros: Verbas para divulgação e confecção de textos para as atividades } \\
\text { (Oficina de produção de texto). Verba para a aquisição de materiais de papelaria, locação } \\
\text { de filmes, etc que sejam necessários para a realização das atividades. }\end{array}$ \\
\hline $\begin{array}{l}\text { Resultados } \\
\text { esperados }\end{array}$ & $\begin{array}{l}\text { Com esse programa espera-se incentivar os alunos a utilizarem as mais diversas } \\
\text { ferramentas de pesquisas, bem como despertar a consciência de que o uso da biblioteca } \\
\text { pode ir além da simples consulta ao livro. } \\
\text { Pretende-se, também, capacitar os alunos para lidarem com a informação, tornando-os } \\
\text { aptos para a vida em sociedade. } \\
\text { Espera-se a participação ativa e cooperativa de professores, direção e bibliotecário. }\end{array}$ \\
\hline
\end{tabular}

O programa foi estruturado pensando nas atividades já realizadas pela equipe do Colégio Pedro II visando sistematizar as atividades para obter um melhor aproveitamento dos recursos e também para efetivar o alcance dos objetivos. Para isso, foram estabelecidos indicadores de avaliação para facilitar o acompanhamento das ações e alcance das atividades propostas.

Dessa forma, as atividades foram elencadas para serem direcionadas para um público específico já que existem necessidades diferenciadas. Ao se propor desenvolver um programa de competência em informação é necessário focar as atividades e etapas nas necessidades da instituição e do público-alvo além de serem adequadas à missão e projeto pedagógico da escola.

Propõe-se que esse programa seja aplicado no Campus Duque de Caxias do Colégio Pedro II como um projeto piloto, que sejam feitos os ajustes necessários e se possível, seja ampliado para outras bibliotecas e salas de leitura do Colégio Pedro II no Rio de Janeiro de acordo com as demandas, realidades e contextos de cada turma. 
Ane Fonseca e Daniela Spudeit

\section{Considerações finais}

A sociedade atual, caracterizada pelo crescente fluxo informacional, necessita da criação de uma consciência crítica e que favoreça a autonomia e a cidadania. A informação está por toda parte, mas nem toda a informação é verdadeira. É por essa razão que o conhecimento das fontes de informação se faz tão importante, por meio delas que se consegue validar a informação utilizada para a construção do conhecimento.

Lidar com a informação atualmente não é simples e nem pode ser feito de maneira negligente, é preciso possuir habilidades que permitam acessá-la, organizá-la, filtrá-la e utilizála de modo eficiente e eficaz. Entretanto, não se pode simplesmente tornar-se um indivíduo competente em informação, existe um processo a ser vivido, processos de ensino e profissionais que interferem diretamente nesse caminho de produção do conhecimento.

Dois dos principais profissionais dessa caminhada são o professor e o bibliotecário escolar que devem trabalhar em conjunto, criando um ambiente propício ao ensino e usando diferentes estratégias para tornar a aprendizagem significativa, possibilitando assim que os alunos criem ligações entre o que foi ensinado e as experiências que eles carregam.

A falta desse trabalho cooperativo torna-se prejudicial ao aluno, pois o mesmo é privado de experiências e ensinamentos que contribuiriam para a sua formação, como, por exemplo, aprender a pesquisar, a acessar fontes de informação, a exercer sua criatividade e criar hábitos de leitura, ou seja, a formação do aluno com alguém competente informacionalmente fica prejudicada, pois o aluno não sabe como lidar com a informação, não sabe como usar as ferramentas corretas e nem a quem pedir ajuda.

O ensino fixo em sala de aula, voltado para o professor e para o livro didático, como únicas fontes de informação, criam um aprendizado mecânico e sem significado, não permitindo que o aluno crie ligações cognitivas e prejudicando a construção do conhecimento. Já a biblioteca isolada e o bibliotecário guardião do acervo impedem que o aluno exerça a sua curiosidade e supra a sua necessidade informacional. Ao se isolar, o bibliotecário atrapalha o processo criação de habilidades necessárias para lidar com a informação e faz com que o aluno perca o local onde poderia desenvolver suas ideias, criar hábitos de leitura e crescer como pessoa. 
O trabalho cooperativo entre bibliotecários e professores para o desenvolvimento da competência em informação: criação de um programa voltado para alunos do ensino médio

A biblioteca escolar possui o papel de ser transdisciplinar, ou seja, ser o lugar onde o aluno vai criar links e interligará informações, construindo novos conhecimentos que serão aplicados de maneira racional nas decisões tomadas ao longo da vida.

Portanto, professores e bibliotecários devem atuar de maneira positiva e preparar os alunos para a vida fora dos muros escolares, prepará-los para viverem em sociedade e para cumprirem os seus papeis como cidadãos, como eleitores e futuros chefes de famílias.

No Colégio Pedro II, o trabalho para o desenvolvimento da competência em informação encontra-se em estágio inicial, porém já existe a parceria entre bibliotecário, direção pedagógica e professores na unidade de Duque de Caxias. Esse fato mostra-se uma tentativa promissora de trabalho colaborativo para o sucesso do programa na escola.

As atividades realizadas pela biblioteca mostram as tentativas de trabalhar com os alunos em prol do desenvolvimento de habilidades necessárias para o uso da informação, atraindo-os para a leitura e para a importância da realização da pesquisa de maneira correta.

Cabe destacar o Cine+Biblio como um bom exemplo do trabalho colaborativo presente nessa instituição. Trata-se de uma ideia do diretor pedagógico, aceita pelo bibliotecário e realizada com a colaboração dos professores. Sua aderência por parte dos alunos mostra como essa cooperação é necessária e benéfica, já que com essa atividade foi possível apresentar aos alunos uma nova fonte de pesquisa e permitiu a criação de links entre filmes, livros e realidade.

Assim sendo, a sugestão de um programa para o desenvolvimento de competências em informação, visa justamente auxiliar e sistematizar a equipe do Colégio Pedro II para a efetiva realização dessas atividades e incentivar ainda mais o trabalho cooperativo entre professores, bibliotecário e direção pedagógica, buscando resgatar as ações já realizadas na escola e incrementá-las, a fim de possibilitar ao aluno o desenvolvimento de habilidades, necessários para o uso da informação de maneira segura e sábia, impedindo, dessa forma, o uso inadequado da mesma.

Ao crescerem em um ambiente cooperativo, de incentivo à leitura, à pesquisa e ao pensamento reflexivo, os alunos poderão desenvolver as competências necessárias para lidar com a informação da sociedade contemporânea, tornando-se um cidadão de pensamento crítico, decisões pautadas em fatos e dados reais, conferidos através das fontes e atuante na sociedade de maneira positiva. 
Ane Fonseca e Daniela Spudeit

A competência em informação deve ser pensada nas escolas desde os primeiros anos escolares das crianças, tornando-se assim um processo iniciado na infância. Todavia, esse processo não terá fim, trata-se de uma aprendizagem que ficará ao longo da vida e que com o passar dos anos irá incorporar novos conceitos e se moldará as mudanças necessárias.

Acredita-se que mais pesquisas sobre esse assunto precisam ser desenvolvidas para que se desperte o entendimento da importância da biblioteca escolar e do trabalho cooperativo entre professores e alunos, para a formação de uma sociedade mais justa e igualitária, composta por cidadão críticos, reflexos, autônomos e preparados para viver ativamente na sociedade contemporânea.

\section{Referências}

AMERICAN LIBRARY ASSOCIATION. Presidential committee on information literacy: final report. Chicago: American Library Association, 1989. Disponível em:

<http://www.ala.org/acrl/publications/whitepapers/presidential>. Acesso em: 03 jun. 2015.

AQUINO, M. A. Cenários, espaços e linguagens: uma nova agenda para pensar, conhecer, agir sobre percursos de formação na sociedade da aprendizagem. Informação \& Informação, Londrina, v. 1, n. 1, p. 26-59, jan./jun. 2012. Disponível em:

http://www.uel.br/revistas/uel/index.php/informacao/article/view/7807>. Acesso em: 18 fev. 2015.

BELLUZZO, R. C. B. Curso de competência em informação. Campinas: UNICAMP, 2005. Slides.

Como desenvolver a competência em informação (CI): uma medida integrada entre a biblioteca e a escola. CRB-8 Digital, São Paulo, v. 1, n. 2, p. 11-14, out. 2008. Disponível em: <http://www.revista.crb8.org.br/index.php/crb8digital/article/viewFile/25/25>. Acesso em: 29 mai. 2015.

; KOBAYASHI, M. C. do M.; FERES, G. G. Information literacy: um indicador de competência para a formação permanente de professores na sociedade do conhecimento. Educação Temática Digital, Campinas, v. 6, n. 1, p. 88- 99, dez. 2004. Disponível em: <https://www.fe.unicamp.br/revistas/ged/etd/article/view/2009>. Acesso em: 18 jun. 2016.

.; FERES, G. (Org.). Competência em informação: de reflexões às lições aprendidas. São Paulo: FEBAB, 2013.

BRASIL. Ministério da Educação. Colégio Pedro II. Portaria n 2810, 01 de abril de 2014. Brasília, 2014.

Brasília, 2001.

Ministério da Educação (MEC). Projeto Político-Pedagógico Colégio Pedro II. 
O trabalho cooperativo entre bibliotecários e professores para o desenvolvimento da competência em informação: criação de um programa voltado para alunos do ensino médio

CAMPELLO, B. O. A escolarização da competência informacional. Revista Brasileira de

Biblioteconomia e Documentação: Nova série, São Paulo, v. 2, n. 2, p. 63-77, dez. 2006. Disponível em: <http://rbbd.febab.org.br/rbbd/article/view/18>. Acesso em: 18 jun. 2016.

Letramento informacional: função educativa do bibliotecário na escola. Belo Horizonte: Autêntica, 2009.

CAREGNATO, S. E. O desenvolvimento de habilidades informacionais: o papel das bibliotecas universitárias no contexto da informação digital em rede. Revista de

Biblioteconomia e Comunicação, Porto Alegre, v. 8, p. 47-55, 2000. Disponível em: 〈http://eprints.rclis.org/13617/1/artigoRBC.pdf>. Acesso em: 03 jun. 2015.

CÓLEGIO PEDRO II. 2011. Histórico. Disponível em:

<http://www.cp2.g12.br/ocolegio/historico.htm>. Acesso em: 05 jun. 2015.

DELORS, J. et al. Educação: um tesouro a descobrir: relatório para a UNESCO da Comissão Internacional sobre Educação para o século XXI. 6. ed. São Paulo: Cortez; Brasília: UNESCO: MEC, 2010.

DUDZIAK, E. A. A information literacy e o papel educacional das bibliotecas. São Paulo, 2001. 177f. Dissertação (Mestrado em Ciência da Comunicação) - Escola de Comunicação e Artes da Universidade de São Paulo, São Paulo, 2001.

Information literacy: princípios, filosofia e prática. Ciência da Informação, Brasília, v. 32, n. 1, p. 23-35, jan./abr. 2003. Disponível em: <http://revista.ibict.br/ciinf/index.php/ciinf/article/view/123 >. Acesso em: 15 jun. 2015.

FREIRE, P. Pedagogia da autonomia: saberes necessários à prática educativa. 47. ed. Rio de Janeiro: Paz e Terra, 2013.

GASQUE, K. C. G. D. Arcabouço conceitual do letramento informacional. Ciência da Informação, Brasília, v. 39, n. 3, p. 83-92, set./dez. 2010. Disponível em: <http://www.scielo.br/pdf/ci/v39n3/v39n3a07.pdf >. Acesso em: 18 jun. 2016.

Letramento informacional: pesquisa, reflexão e aprendizagem. Brasília: FCI/UnB, 2012. Disponível em: 〈http://repositorio.unb.br/bitstream/10482/13025/1/LIVRO_Letramento_Informacional.pdf $>$. Acesso em: 08 dez. 2015

.; TESCAROLO, R. Sociedade da aprendizagem: informação, reflexão e ética. Ciência da Informação, Brasília, v. 33, n. 3, p. 35-40, set./dez. 2004. Disponível em: <http://www.scielo.br/pdf/ci/v33n3/a05v33n3 > . Acesso em: 18 jun. 2016.

KUHLTHAU, C. Carol Collier Kuhlthau. 2004. Disponível em: $<$ https://comminfo.rutgers.edひ k kuhlthau/research_interests.htm>. Acesso em: 05 jun. 2015

Como usar a biblioteca na escola: um programa de atividades para o ensino fundamental. 3. ed. Belo Horizonte: Autentica, 2013.

MAROTO, L. H. Biblioteca escolar, eis a questão!. 2. ed. Belo Horizonte: Autêntica, 2012. 
Ane Fonseca e Daniela Spudeit

MOREIRA, M. A.; MASINI, E. F. S. Aprendizagem significativa: a teoria de David Ausubel. São Paulo: Moraes, 1982.

MORO, E. L. S.; ESTABEL, L. B. O encantamento da leitura e a mágica da biblioteca escolar. Educação em Revista, v. 7, n. 40, out. 2003.

ONTORIA PEÑA, A. Mapas conceituais: uma técnica para aprender. São Paulo: Loyola, 2005.

ROCA, G. D. Biblioteca escolar hoje: recursos estratégicos para a escola. Porto Alegre:

Penso, 2012.

SILVA, M. A. Biblioteca escolar e educação. In: SEMINÁRIO DE BIBLIOTECA

ESCOLAR: ESPAÇO DE AÇÃO PEDAGÓGICA, 3., 2004, Belo Horizonte. Anais

eletrônico... Belo Horizonte: UFMG, 2004. Disponível em:

<http://gebe.eci.ufmg.br/downloads/323.pdf>. Acesso em: 18 jun. 2016.

UNESCO. Ensinar e aprender: alcançar a qualidade para todos: relatório de monitoramento global de educação para todos. Paris: ONU, 2014. Disponível em:

<http://unesdoc.unesco.org/images/0022/002256/225654por.pdf $>$. Acesso em: 18 jun. 2016.

Artigo submetido em: 22 mar. 2016

Artigo aceito em: 05 jun. 2016 